\title{
The Diffusion of Instructional Video Technique among Open and Distance Learners in Nigeria
}

\section{Chuks ODIEGWU-ENWEREM ${ }^{1}$, Lai OSO ${ }^{2}$, Lanre AMODU ${ }^{3}$, Uche CHUKS-ENWEREM ${ }^{4}$ and Nelson OKORIE ${ }^{5}$}

\author{
1,3,5 Department of Mass Communication Covenant University Ota, Ogun State, Nigeria \\ ${ }^{2}$ School of Communication, Lagos State University, Ojo, Lagos, Nigeria \\ ${ }^{4}$ Faculty of Education Administration, University of Benin, Benin City, Nigeria
}

Correspondence should be addressed to: Chuks ODIEGWU-ENWEREM; chuks_enwerem@yahoo.com

Received date: 10 September 2019; Accepted date: 26 October 2020; Published date: 30 December 2020

Academic Editor: Joshua Chukwuere

Copyright (C) 2020. Chuks ODIEGWU-ENWEREM, Lai OSO, Lanre AMODU, Uche CHUKS-ENWEREM and Nelson OKORIE. Distributed under Creative Commons Attribution 4.0 International CC-BY 4.0

\begin{abstract}
The National Open University of Nigeria in 2014 introduced instructional video technique to enhance distance learning and expected students to embrace it to improve their learning capacity. However, students' awareness and adoption of the technique has not been assessed. This study investigated NOUN students' awareness, perception and adoption of the technique within the first 24 months of its introduction. Anchored on the technology diffusion of innovation theory, the research sought to discover the awareness level, and attitude of students and their adoption of the initiative within the period. Survey method was used with structured questionnaire administered to 120 respondents selected purposively from four study centres in Lagos, Port Harcourt, Owerri, and Abuja. Data were analyzed using simple percentage and cross tabulation. Findings show that the percentage of students who knew about and adopted it was still quite low after two years of its introduction. The majority of the students, however, showed a positive disposition towards the new method of teaching. The result further showed that most of the students got their information about it from their colleagues, rather than from the official communication channel of the university. The study concluded that even though the instructional video technology was positively perceived, most of the target students were not aware of it in good time due mainly to poor communication. The paper recommends that in future, the introduction of any innovative, technology-based idea, especially targeted at students, should be properly publicized in order to secure popular cooperation of the key target audience.
\end{abstract}

Keywords: Adoption, Computer-mediated, Innovation, Instructional video, NOUN, Perception

Cite this Article as: Chuks ODIEGWU-ENWEREM, Lai OSO, Lanre AMODU, Uche CHUKS-ENWEREM and Nelson OKORIE (2020)," The Diffusion of Instructional Video Technique among Open and Distance Learners in Nigeria", Journal of e-Learning and Higher Education, Vol. 2020 (2020), Article ID 290107, DOI: $10.5171 / 2020.290107$ 


\section{Introduction}

The rapid increase in open and distance learning method in higher education is no doubt a response to the need to increase access to learning to more people than the conventional institutions could possibly provide. While this method is attractive to many, there have been some problems associated with learning at a distance. According to Iilonga, Ashipala, \& Tomas, (2020) and Guri-Rosenblit (2013), Open and Distance Learning (ODL) method of instruction is associated with such challenges as lack of person-to-person interaction as well as group discussion among students, due to the existing distance between learners and educators. To enhance learning experience of students, the National Open University of Nigeria, (NOUN), therefore, introduced a web-based, interactive method known as instructional video. Being a technologybased innovation, however, problems of perception, attitude, and adoption of the technique were thought to be capable of affecting the effectiveness of the programme (Koohang, Milwaukee, Durante, Lewis, 2003). Oyekunle, Oladele, \& Afolayan, (2017) also contend that digital divide, as well as technophobia are some of the hindrances associated with learning from a distance. Consequently, this study was embarked upon to investigate NOUN students' attitude and adoption of this innovation some years after it was introduced.

Some of the factors that determine instructional strategies include: the level of students' development, the objectives set by the teacher, the learning content as well as the environment ( i.e. time, physical setting and resources) that are required. Students' expectations also come to play as a deciding factor of what strategy to adopt. In their study titled, "Teaching and evaluation methods preferred by university students, Justicia, Fuente Arias, Marinez and Berben (2005) concluded that individual differences emerged as factors in students' expectations of the appropriate methods preferred. This implies that no single method is likely to meet all the learning goals. Similarly, Sander (2005) opined that due to changes in higher education, in terms of class structure, diversity and students' participation, teachers need to regularly seek to understand students' expectations of teaching, learning and assessment.

While some methods would be appropriate in a classroom setting, others are better in an online environment. Some tested methods of instruction include a selflearning instructional material packaged for students to use as a guide in their learning; mastery learning, which involves students being presented with information to be learned at a predetermined level of mastery; in this case, class is tested while poor performers are re-taught and retested; Mixed-mode instruction, which is a combination of 'on-line' and "face-toface" methods; and On-line instruction and learning, being a self-directed and automated approach to learning and it utilizes hypermedia (internet browsers, etc.), and gives users the freedom to act unrestrained by lack of physical classrooms (Petrina nd).

According to UNESCO (2002), the purposes of communication includes:

the distribution of information and enhancing the interaction between teachers and learners and where possible between learner and learner. In some forms of distance education this learner interaction is absent; however in some cases it is considered important and may be provided in one way or the other. The advent of new technology has made the organization of "virtual groups" possible, and in countries with adequate internet penetration, this is a fast growing approach to distance teaching

Video is designed with the capacity to convey material through auditory and visual channels, create a multisensory learning environment, yet there is a need to 
know what students respond to, and their perception of effectiveness of instructional video. In the case of the National Open University instructional video, what would have been the initial reception of the initiative by students and through what channels did the students learn about the technique, what was their rate of adoption, etc.?

\section{Statement of the problem}

Open and Distance Learning (ODL) method of teaching is faced with some challenges such as increased workload, problems of adapting to technology, difficulties with online course management, insufficient training among others (Fojtik, 2018; Mohanachandran \& Ramalu, 2013; Moisio \& Smeds, 2004; Shaik, 2005; Wagner, Hassanein \& Head, 2008). In an effort to mitigate some of the problems, the National Open University of Nigeria (NOUN) introduced the instructional video technology in 2014 (National Open University Profile, 2015). The technique was expected to be embraced by students to improve their learning ability. However, little was known about students' awareness and adoption of the innovation within the time of its introduction. Moreover, being a technology-based innovation, perceptions and attitudes by the target students may affect the effectiveness of the programme (Ilie, Slyke \& Lou, 2005; Rogers, Singhal \& Quinlan, 2003). Diffusion, which is the process by which the new method gets accepted, adopted and spread among the intended audience, is of interest in this study and for future adaptation of strategies. Thus arises the need for the investigation of the acceptance, adoption and utilization by the students of the University under reference.

The research objectives guiding the study are:

To determine:

1. The extent to which students were aware of the instructional videos;

2. The initial attitude of students towards the innovation;
3. The extent to which students adopted the technique and at what time;

4. The extent to which students perceived the technique to be useful.

The Research questions

5. Were students aware of the instructional videos and from which channels?

6. What was the initial attitude of students towards the innovative instructional videos?

7. Did the students adopt the technique and at what time?

8. How useful students perceived the technique to be?

\section{Conceptual Clarifications}

\section{Innovation}

According to Viatomi, Muse and Suluka (2018), innovation involves doing new things or doing existing things in a new way; innovation is the hallmark of entrepreneurs who make use of their imaginative minds to do new things and exploit opportunities. Abubakar, Ibrahim and Yazeed (2018) state that innovation plays a part in moderating the entrepreneurship education and entrepreneurship relationship. A person of innovation is seen as a practical dreamer who does his homework well; he does not dwell on the status quo but rather continues to search for change with the hope to make success of his endeavour. Although innovation may be seen by many as being peculiar to the entrepreneur, however, in this paper, it is also applicable to the government's ability to apply new and creative methods in solving existing problems and

achieving substantial results. As in the case of an entrepreneur that is a risk taker, the government that applies innovative approaches to problem solving is definitely a bold and creative one. 


\section{Diffusion}

According to Halton (2019), updating on Rogers (1962) idea, he defines diffusion of innovation as a process in a social system (such as the Nigerian society), where an innovative idea or concept (such as the deployment of instructional video) is spread among members of the social group through certain channels, including the mass media. Diffusion in the pure sciences refers to the net movement of molecules from a region of high concentration to one of lower concentration; either in a solid, liquid or gaseous state. Diffusion in this context refers to the process in which the knowledge/awareness of the introduction of the instructional video was spread among the students of the National Open University of Nigeria (from the area of concentration of knowledge (i.e., NOUN Management) to the area of least knowledge - the students).

\section{Theoretical Framework}

\section{Diffusion of Innovation}

The relevant theory in this discourse is the Diffusion of Innovation theory, propounded by Everett Rogers (1962); it tries to explain how, why, and at what rate new ideas and technology spread within the social system through the use of communication. Rogers (2003) further posits that adoption means a decision to fully adopt or decide to use an innovation as the best course of action available while rejection means not to use an innovation. He defines diffusion as the process by which a new idea is communicated through certain channels over time among the members of a social system. Katz (1957) introduced the notion of the two groups: opinion leaders and opinion followers, explaining how the media interact to influence them. According to Toews (2003), Tarde (1903) was the first to plot the original S-shaped diffusion curve. Ryan and Gross (1943) added the adopter categories while Rogers (1962) popularized them in addition to listing the categories of adopters as: innovators, early adopters, early majority, late majority, and laggards. Early adopters are considered extremely critical to innovations. Innovators are found to be in the smallest percentage $(2.5 \%)$; the early majority and late majority occupy the largest share of the spectrum with (34\%) each; while laggards (16\%) and early adopters $(13.5 \%)$ follow in that order. This order is significant for Management, such as the National Open University of Nigeria, to understand the dynamics of adoption of the instructional video technique by the target students. Rogers' diffusion of innovations theory is, therefore, considered appropriate for examining the extent of adoption of the instructional video technique among students of the National Open University of Nigeria (Medlin, 2001; Parisot, 1995).

\section{Literature Review}

In their study of students' social networking behavior anchored on Diffusion of Innovation Theory, Odundo, 2003 and Zeeb, (2004) found that compatibility and complexity, as well as trialability and relative advantage significantly influenced the use of social networking among the group studied. They conclude that the rise in social networking use by students appears to be influenced by a social circle incentive - where group members are seen to be enjoying more social interaction; hence pressure mounts for others to belong to this communication circle. MCwhorter (2010) studied early adopters of innovation and identified both organizational and environmental factors as being statistically significant factors. He, however, observed that organizational influences weighed more than environmental influences when it comes to determining innovation adoption rate in hospitals. Furthermore, the factors associated with the rate of innovation among hospitals and specifically influencing the early adoption of innovation were found to be organizational complexity, size, slack resources, control of domain, and the presence of a competitor with magnet designation. Organizational and environmental factors combined to exert a significant influence on the rate of early adoption of nurse magnet programs within hospitals. 
Some studies, for example, Dunn, (1983) and Chang, (2010) suggest that the instructional methods adopted by teachers can have significant influence on learning achievement - further implying that appropriate instructional methods make the understanding of new concepts easier while inappropriate methods have the tendency to cause a drawback to knowledge acquisition, retention and application. The implication, therefore, is that educators, as well as managers, must always try and align their instructional methods with students' needs and preferences in order to enhance overall learning.

In the case of ODL learners, a combination of methods, including Instructional Video Methods, would be considered quite apt to achieve high level of knowledge acquisition. According to Odundo (2003) and Zeeb (2004), students whose learning preferences are not appropriately matched with instructional methods may not develop interest in the subject matter, which may cause some to drop out altogether. Dunn (1983) found that the instructional methods used by teachers significantly influenced students' leaning achievement, further emphasizing that the methods used to deliver lessons were of more impact than the course content. Chang (2010) investigated the effectiveness of teacher-centered and learner-centered methods on students' performance and found that learnercentered methods were more effective in influencing the perception of students towards science subjects. It further showed that students placed more value on active participation in-group discussions than attendance of lectures as well as improvement of overall relationships, Amodu (2012).

Odiegwu-Enwerem (2014) observed that social networking is being highly embraced by students because of social circle incentives. This means that students believe that belonging to the group enhances their social interaction; hence there is pressure to belong in this communication circle. In his own study, MCwhorter (2012) found that organizational as well as environmental factors significantly influenced early adopters of innovation. He, however, found organizational influences to be stronger than environmental influences in determining the rate of adoption of innovation in hospitals.

\section{Methodology}

\section{Sample and Sampling Technique}

The study adopted survey to gather quantitative data. One hundred and twenty (120) students of the National Open University of Nigeria were purposively and conveniently selected from four Study Centres selected based on: (1) adequate spread between the various geo-political zones of the country; (2), Convenience, indicating some measure of ease of identifying and engaging students, and (3), cost of reaching many students. The four NOUN Study centres were: Lagos, Owerri, Port Harcourt and Abuja - all representing various geographical regions of Nigeria.

A 22-item questionnaire was developed and used to obtain information from the respondents/students of NOUN in the sampled centres and the unit of analysis was each of the students that were interviewed either one-on-one or through the questionnaire. The questionnaire was initially sent via the respondents' email addresses as supplied by NOUN ICT department. However, the response was not adequate as only about 24 percent (55) responses were received out of about 200 copies sent out, hence the resort to physical administration and filling of the questionnaire. All together, 115 copies of the questionnaire were analyzed from across four study centres. The exercise covered about 30 days between August and September. Google Form, an analytical research tool developed by Google Incorporated was used to create the questionnaire template as well as achieve accurate analysis thereafter.

\section{Data Presentation and Analysis}

In this section, the results of the quantitative data are presented and 
discussed in line with the research questions.

Table 1: Students Awareness of the Instructional Video

\begin{tabular}{|c|c|c|}
\hline S/N & Response Category & Response (\%) \\
\hline & Yes, I was aware & 72.2 \\
\hline 2 & No, I was not aware & 27.8 \\
\hline 3 & Can't tell & 0 \\
\hline 4 & Total & 100 \\
& & $\mathrm{n}=115$ \\
\hline
\end{tabular}

Source: Researcher's field work, 2016

Table 1 above shows that a good majority of the students/respondents (72.2 percent) said that they were aware of the newly introduced instructional method. Only 27 percent said they were not aware of it as at the time of the field work. This gives the impression of a good figure; however, the second item which sought to know when they became aware of it showed that the majority (59.1\%) heard about it in the second half of the second year of its introduction - (2016).
On their source of information about the instructional video, (28.9 \%) mentioned their colleagues as their first source of information, implying reliance on grapevine instead of official channels. This was followed by NOUN Lecturers (23.3\%) and Study Centre notice boards (22.2\%). Twenty one percent of the students said they learnt about it from NOUN websites while only one percent said the information was received from the mass media.

Table 2: Students' Attitude to/Perception of Instructional Video

\begin{tabular}{|c|c|c|}
\hline $\mathbf{S} / \mathbf{N}$ & Category & Response (\%) \\
\hline $\mathbf{1}$ & Positive & 21.7 \\
\hline $\mathbf{2}$ & Negative & 29.7 \\
\hline $\mathbf{3}$ & Neutral & 48.6 \\
\hline & Total & $\begin{array}{c}100 \\
\mathrm{n}=115\end{array}$ \\
\hline
\end{tabular}

The initial attitude/perception of students about the innovation was another item of study. The majority of the respondents indicated that they were positively disposed to the idea; they discussed it with their colleagues, got positive feedback $(29.7 \%)$, and neutral feedback (48.6\%) both of which combined also encouraged them to go ahead with the new idea. This trend is consistent with the tenets of the diffusion and innovation theory. In this regard, awareness of the new technology, as well as influence of opinion leaders, including peers, are considered factors in its adoption.

Table 3: Time of adoption of the technology

\begin{tabular}{|c|c|c|}
\hline $\mathbf{S} / \mathbf{N}$ & Category & Response \% \\
\hline $\mathbf{1}$ & Immediately & $13.6 \%$ \\
\hline $\mathbf{2}$ & Delayed for a while & 77.3 \\
\hline $\mathbf{3}$ & Total & $\begin{array}{c}100 \\
\mathrm{n}=115\end{array}$ \\
\hline
\end{tabular}

Source: Researcher's field work 
As the table indicates, the majority of the respondents $(77.3 \%)$ said that they did not start using the technology immediately they heard about it for reasons they could not explain. Only 13.6 percent said they adopted it immediately. Among those who delayed for a while before starting to use the method, 59.4 percent says they cannot say who or how they were eventually motivated; (9.4\%) said they were motivated and encouraged by their colleagues while (15.7\%) said they were motivated and encouraged by their academic counselor/lecturer. This also goes to confirm the importance of the third party role in the new technology adoption framework.

Table 4: Students perceived usefulness of instructional video

\begin{tabular}{|c|c|c|}
\hline S/N & Category & Response \% \\
\hline $\mathbf{1}$ & Very useful & 29.3 \\
\hline $\mathbf{2}$ & Useful & 46.7 \\
\hline $\mathbf{3}$ & Not Useful & 12 \\
\hline $\mathbf{4}$ & Not Useful at all & 2.7 \\
\hline $\mathbf{5}$ & Can't say & 9.3 \\
\hline $\mathbf{6}$ & Total & 100 \\
\hline
\end{tabular}

Source: Researcher's field research work

Table 4 above shows that a good number of the students considered the technology to be useful and therefore worth their effort. Forty-seven percent said the technique was useful, another (29.3\%) said it was very useful while $(2.7 \%)$ considered it not worth the while. About nine percent could not say if the new method is useful or not.

Other variables were also considered in the study including: students' source of Internet connection which is a major factor for many of them in deciding to utilize this method of instruction; how often they logged unto the platform to access the lectures; what type of experience they had in the process of logging on; they were also asked to comment on their rating of the instructional videos as well as on the various lecturers that they had watched/viewed as they delivered the lectures.

From students' responses, many of them depend on commercial Internet to access their video lectures; a situation that is sure to affect their frequency of use of the technology. In terms of ease of logging in, a total of 58.1 percent of the respondents said they found logging in easy and very easy while a total of 24.4 percent said it was difficult logging in. Another 4.1 percent said the experience varied from difficult to easy while 12.2 could not say exactly what their experiences were. It is gratifying to note that a good majority of the students are comfortable with the technology, even though a lot more needs to be done by them to properly key into the technique without much ado.

In the estimation of the students, many variables were considered to describe how effective the various lecturers were in their lecture delivery. These include: clarity of presentation; body movement while making the presentation; mastery of subject matter, visual demonstration, appropriate dressing, facial expression and non-verbal cues. Among these, the respondents selected clarity of the presentation (46.3\%) and subject matter mastery $(26.8 \%)$ as the most important factors that account for lecture effectiveness. Other factors such as body movement, visual demonstration and nonverbal cues received low rating from the students, which means that they did not consider those factors as being strong enough. In the same vein, the respondents 
said the content of the video and the lecturers themselves were the main attraction.

\section{Overall effectiveness of the lectures}

Respondents' rating for the various lectures showed that 13 percent found the lectures very effective as a learning method; $44.4 \%$ found them effective, while $24.1 \%$ said they were not effective for them as a delivery method. Ten percent were undecided on their effectiveness. This shows that a good majority of the students - 57.4 percent considered the method of delivery to be effective and therefore deserved to be sustained.

\section{Discussion of Findings}

The study established that the majority of the students/respondents were aware of the newly introduced instructional method even though their sources of information differed from person to person. The implication is that within the university body, grapevine sources seem to be popular as sources of information rather than the official channel of communication. The university has a duty to improve on its information dissemination mechanism especially to its core target - the students to avoid the incidence of 'fake' news intruding into the mix.

As enumerated by Rogers (ibid), there are four main factors that affect the adoption of innovation: (1) the innovation, (2) communication channels, (3) time, and (4) the social system. The communication channel is the means by which messages are transmitted from one individual to another. In this regard, NOUN had the opportunity of communicating the innovation through many channels: the mass media, official websites, notice boards, etc. and should be encouraged to exhaust these subsequently.

The findings also show the attitude of students towards the new innovation, indicating that the majority of the respondents were positively disposed to the idea. This positive disposition did not happen immediately but followed a series of actions including discussing it with their colleagues who gave them positive feedback which encouraged them to go ahead with the new idea. This trend is consistent with the tenets of the diffusion and innovation theory. In this regard, awareness of the new technology, as well as influence of opinion leaders, including peers, proved to be key factors in its adoption.

The study also found that students adopted the innovation but in phases as the majority of them did not start using the technology immediately they heard about it for different reasons. Only a few adopted it immediately. These few fall within the first phase of Diffusion of Innovations theory referred by Rogers (1961) as 'innovators'. The phases of adoption of the technique agree with the Diffusion of Innovations theory innovation adoption framework typically: - innovators - 2.5\%; early adopters - $13.5 \%$; early majority $34 \%$; late majority $-34 \%$ and laggards $16 \%$ - all with some modifications. The implication in this finding is the critical role which opinion leaders and peer influence play in the adoption and acceptance of new ideas. This may suggest that the informal communication systems appear to have as much influence in changing behavior as the mass media.

The phased adoption observed in the study is in line with the trialability of the theory which refers to the capacity to experiment with the new technology before adoption. On this note, many of the students said they hesitated before adopting the new technology, ostensibly, in that process, they had to try it out, thus affirming this fourth factor by Rogers.

The study links awareness level of the innovation to the perception and adoption of the innovation by the students, as shown by the number of respondents that were not yet aware of the new approach to learning. This also means, that the same percentage of students had not yet adopted the technology as at the time. This shortfall is attributable to communication lapses following the launch/introduction of the innovation. This, therefore, calls for a 
proper programme of publicity and information dissemination about a new innovation to allow the target audience to adequately follow up with the technology.

\section{Conclusion and Recommendations}

The study clearly reveals that the awareness level of the launch and introduction of NOUN Instructional Video Technology was quite low, occasioning low adoption of the technology among the sampled population. Even though this study is a pilot, it, no doubt, can subsist as a representative of the larger population of students in the other geopolitical zones of the country. It, however, revealed a high level of interest and positive disposition of the students, (including both those who knew about the video technology and those who were just learning about it). By being positively disposed to the new technology, the students stand a good chance of adopting the technology and imbibing the tenets in a short while. A need for an enlarged study of the entire regions of the federation is recommended as the programme enters its third year.

Because most of the students from the study centres in the South-east, Southsouth and North-central - indicated low awareness as against students in Lagos centres, the point can be made that urban dwellers appear to be exposed to new innovations faster than regional or local dwellers. This situation clearly shows that the so much touted world being a global village, where urban dwellers may not necessarily have much advantage over rural dwellers, is not yet applicable in Nigeria.

It is hereby recommended that this gap can be narrowed down by involving all study centres across the nation with a view to streamlining their communication before the takeoff of any important programme affecting students. In this regard, rather than causing the students to access information from their colleagues, there should be publicity/communication plan using such tools as: University website, bulletin boards, as well as SMS (Short Message Services), among others, which students indicated as part of their sources of information.

The paper also recommends that lecturers or educators should endeavour to create some platforms for reaching out to their students online. This could be in the form of blogs and special interactive platforms and keeping in touch regularly. Through such blogs, new developments within the academic community could be passed on to the students seamlessly. Through this method, students would feel at home being in contact with their lecturers virtually as well as feel free to ask questions for clarification.

\section{Acknowledgement}

The authors would like to thank the Management of Covenant University for providing sponsorship for this programme.

\section{References}

- Abubakar, S. A., Ibrahim, N. A. \& Yazeed, M. (2018). The moderating role of innovativeness on the relationship between entrepreneurship education and student entrepreneurship intention. Covenant Journal of Entrepreneurship, 2 (2), 1 - 13

- Amodu, L. O. (2012) Relations between multinationals and host communities in Nigeria's Niger Delta: A stakeholder perspective. Journal of Media \& Communication, 3(1), 143160

- Bales, S. (2014). Why are early adopters so critical to innovation? Retrieved from: https://www.scottebales.com

- Ceccucci, W. \& Sendall, P. (2010). Conference on information systems applied research 2010 CONISAR Proceedings Nashville Tennessee, USA v3 $n 1526$

- Cruikshank, D., Jenkins D. B. \& Metcalf, K. K. (2011). The act of teaching ( $6^{\text {th }}$ Ed.). McGraw-Hill: New York

- Dunn, R. (2009). Learning Style: State of the Science. Lawrence 
Erlbaum Associate. Retrieved from: http://www.jstor.org.

- Fojtik, R. (2018). Problems of distance education. ICTE Journal. $7(1)$; 14-23. DOI:10:2478/ijicte2018 - 0002

- Guri-Rosenblit (2013). Challenges facing distance education in the $21^{\text {st }}$ century: Policy and research implications. Retrieved from: https://www.resaechgate.net

- Halton, C. (2019). Diffusion of innovations theory, Retrieved from: https://www.investopia.com

- Ilie, V., Slyke, C. V., \& Lou, H. (2005). Gender differences in perceptions and use of communication technologies: A diffusion of innovation approach. Information Resources Management Journal 18(3),13-31

- Iilonga, A., Ashipala, D. 0. \& Tomas, N. (2020).Challenges experienced by students studying through Open and Distance Learning at a higher education institution in Namibia: Implications for strategic planning, The International Journal of Higher Education, 9(4), 116-12

- Katz, E. (1957). The two-step flow of communication: An up-to-date report on an hypothesis. Political Opinion Quarterly. 21(1), 61 - 78

- Koohang, A. \& Durante, A. (2003). Learners' perceptions toward the Web-based distance learning activities/assignments portion of an undergraduate hybrid instructional model Journal of Information Technology Education 2(1), 104-113

- MCwhorters, J. (2010). A study of early adopters of innovation. A PhD dissertation submitted to the University of Alabam, Birmingham

- Medlin, B.D. (2001). The factors that may influence a faculty member's decision to adopt electronic technologies in instruction (Doctoral dissertation, Virginia Polytechnics institute and State University, 2001). ProQuest Digital Dissertations

- Mohanachandran, D. K. \& Ramalu, S. S. (2013). Work and schooling challenges of open distance learning: A case study, Research Journals of
Social Sciences and Management, 2(1), 198 - 207

- Moisio, A, \& R. Smeds. (2004). Elearning: A service offering, Knowledge and Process Management, 11(4), 252-260.

- National Open University of Nigeria, NOUN, Profile, 2015.

- Odundo, P. A. (2013). Effects of application of instructional methods on learner achievement in business studies in secondary schools in Kenya, International Journal of Education and Research 1(5), 1 - 22

- Oyekunle, R. A., Oladele, O. T. \& Afolayan, F. F. (2017). The paperless classroom: Views of the University of Ilorin undergraduate students. Nigerian Journal of Educational Technology, 1(2), 72 - 86

- Parisot, A. H. (1995). Technology and teaching: The adaptation and diffusion of technological innovation by a community college faculty. Doctoral dissertation submitted to Montana State University, Montana, U.S.A, Pearson Prentice Hall.

- $\quad$ Peslak, A., Ceccucci, W \& Sendall, P. ( 2012). An empirical study of social $n$ etworking behaviour using theory of reasoned action. Journal of Information Systems Applied Research, 5 (3), 12-23

- $\quad$ Petrina, S (nd, in press). Curriculum and instruction for technology teachers, pp. 125 - 153

- Premkumar, G. \& Ramamurthy, K, (1995). The role of interorganizational and organizational factors on the decision mode for adoption of interorganizational systems. A journal of decision Science Institute. 26(3), $303-336$

- Roblyer, M. D. (2006). Integrating educational technology into teaching. Upper Saddle River:

- Rogers, E.M. (1995). Diffusion of innovation (4th Ed.). New York: Free Press.

- Rogers E. M., Singhal, A., \& Quinlan, M. M. (2018). Diffusion of Innovations and Everett M. Rogers. In D. W. Stacks \& M. B. Salwon (Eds.) 2009. An Integrated Approach to 
Communication Theory and Research (Second Edition), pp. 418 434, NY: Routledge

- Ryan, B. and Gross, N. C. (1943). "The diffusion of two hybrid seed corns in two Iowa rural communities. Rural Sociology.18 (15-24)

- Sander, P. (2005). Researching our students for more effective university teaching. Electronic Journal of Research in Educational Psychology, 5, (3), 113-130

- Siakas, V., Georgiadou, E (1999). Process Improvement: The Societal Iceberg, European Software Process Improvement Conference, EuroSPI '99, Pori, Finland, 25 - 27.10, pp. 2537

- Sobowale I., (1983). Scientific Journalism. Idosa Consult: Lagos

- Tarde, G (1903). The laws of imitation, In Rogers, E. M, (2010). Business and Economics.
- Teo, T.S.H and Tan, M (2000). Factors influencing the adoption of internet banking. Journal of the Association of Information Systems. 1(1)

- UNESCO (2002). Education For All, (EFA) Global Monitoring Report

- Viatonu, O., Muse, S. A. and Suluka, A. B. (2018). Entrepreneurship: A viable panacea to social-political unrest in Nigeria. Covenant Journal of Entrepreneurship, 2 (2) 14 - 23.

- Zeeb, M. S. (2004). Improving students' success through matching learning and teaching styles. In

- Kang'ahi, M, Indoshi, F.C., Okwach, F. O. and Osodo, J. (2012). Teaching styl es and learners'

achievement in Kishwahili language i $\mathrm{n}$ secondary schools. International Jo urnal of Academic Research in Progressive Education and Development. Vol. 1 (3). 